\title{
The role of CRM within retail loyalty marketing
}

Received (in revised form): 1st December, 2003

\section{Richard Cuthbertson}

is a senior research associate at Templeton College, University of Oxford, working on a variety of research projects relating to the strategic modelling and analysis of retailer-consumer and retailer-supplier systems, operations and relationships. He has a wide variety of professional experiences working both in industry and academia, in managerial, consulting, research and teaching positions.

\section{Arttu Laine}

is the Chairman of Prisma supermarkets in Estonia, part of the SOK Group in Finland. He spent a year on secondment to the Oxford Institute of Retail Management at Templeton College, University of Oxford, researching the successful use of individual customer information within major European retailers.

\begin{abstract}
This paper aims to provide an understanding of how a retailer's overall loyalty marketing strategy influences the importance of different customer relationship management (CRM) activities, and provides an insight into the role of CRM within loyalty marketing. From the strategic perspective, CRM may potentially provide benefits for customers, retailers and suppliers, not only in commercial terms, but also in terms of individual and organisational learning and development. These benefits and developments are not, however, universal. By classifying different loyalty marketing strategies, it can be shown that CRM plays a different role within an organisation depending on the marketing strategy adopted. This may have implications for managerial decision making throughout the CRM development life cycle, in terms of appropriate hardware and software platforms to the most relevant analyses and performance measures to adopt. CRM activities may be very effective in enhancing customer loyalty for profit. This can only be achieved through understanding the relevance of such tools and techniques to the overall loyalty marketing strategy and applying them accordingly. Different priorities should be given to different CRM activities, depending upon the particular retail situation.
\end{abstract}

Richard Cuthbertson Oxford Institute of Retail Management, Templeton College, University of Oxford, Kennington Road, Oxford OX1 5NY, UK

Tel: +44 (0) 1865422 590; e-mail: richard.cuthbertson@ templeton.ox.ac.uk

\section{INTRODUCTION}

There are many definitions of customer relationship management (CRM). In broad terms, Galbreath proposes that CRM refers to the:

'activities an enterprise performs to identify, select, acquire, develop, and retain

increasingly loyal and profitable customers'.

This implies that CRM may have an impact on all business activities.
In narrower terms, CRM is often defined in terms of the technology involved.

'CRM is an information industry term for methodologies, software, and usually Internet capabilities that help an enterprise manage customer relationships in an organized way. For example, an enterprise might build a database about its customers that described relationships in sufficient detail so that management, salespeople, people providing a 
service, and perhaps the customer directly could access information, match customer needs with product plans and offerings, remind customers of service requirements, know what other products a customer had purchased, and so forth.'

In either case, CRM aims to provide the necessary knowledge for the retailer's proposition to reflect individual customer requirements. It should be noted, however, that the nature of the process of data capture and customer contact may be as, or more, important than the information captured. This is because customers act both rationally and emotionally. Customer loyalty is more likely to be gained when the customer is won over by both a rational argument, such as lowest price or highest quality, and an emotional bond, such as feeling good shopping at a particular store. This is summarised by Brian Woolf, who stated that 'Man is an economic animal in search of self-importance'. ${ }^{3}$

So, the way in which CRM is implemented is crucial, especially given CRM has the potential to be very expensive and it has been claimed that 'industry studies show that $60 \%$ of CRM software installations fail'. ${ }^{4}$

There are many reasons given for such failures, often relating to CRM being driven by information technologists rather than marketers, as Mitchell states, 'The real problem with CRM is that it is not a marketing-driven concept'.

Indeed, there are many CRM practitioners and researchers outlining the key issues in CRM, such as Davids' 'How to avoid the 10 biggest mistakes in CRM', and Barlow's 'Loyalty marketing: What is its role in a CRM world?'? Such articles are broad in scope and tend to offer similar generic advice: the marketer should make sure they know why they are using CRM; manage the costs, especially those relating to information systems; measure the results; and learn.

More focused work tends to concentrate on the performance measurement and the data analysis aspects of CRM, such as Hirschowitz's 'transforming customer insight into customer value, ${ }^{8}$ and Starkey and Woodcock's 'REAP' (retention, efficiency, acquisition and penetration) measurement. ${ }^{9}$

This paper aims to link these two areas, by providing an understanding of how a retailer's overall loyalty marketing strategy influences the importance of different CRM activities, and provides an insight into the role of CRM within loyalty marketing.

\section{METHODOLOGY}

This research is primarily based on 16 interviews with leading European retailers or their CRM advisers, supported by secondary information. The interviews were conducted over a period of time up to March 2003, with senior managers in charge of loyalty programmes. Averaging around 40 minutes, the interviews ascertained opinions on the retailer's overall marketing strategy and the major roles that CRM plays within the organisation. While this research method provides insight into the strategies adopted by different retailers, its major weakness lies in the subjective and confidentially sensitive nature of the responses. Where possible, quantifiable figures and evidence to back up the views disclosed were requested. In order to comply with confidentiality agreements, however, quotes given from the interviews have generally been made anonymous.

The retailer sample includes a variety of sectors, though it is focused on grocery. The different product categories 


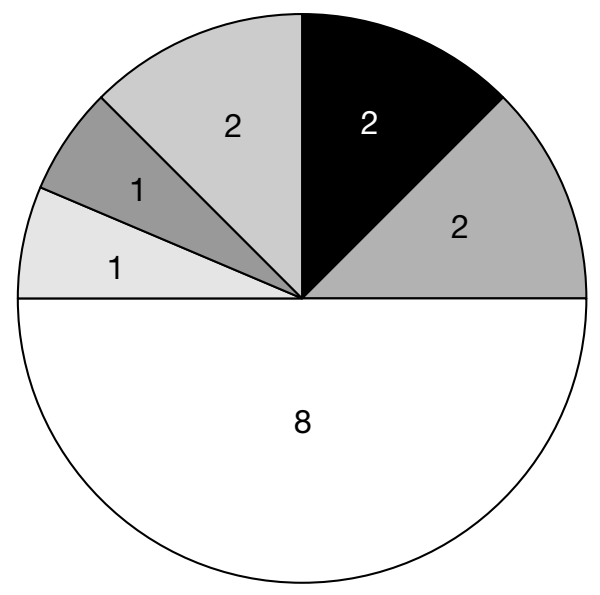

Department/variety store $\square$ Financial services provider $\square$ Grocery

$\square$ Health and beauty

$\square$ Petrol

$\square$ Third party

Figure 1 Retailer sample, main product sector

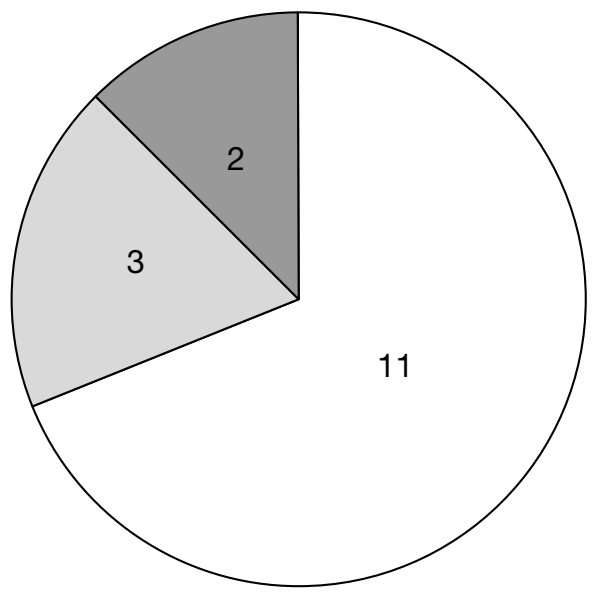

$\square$ UK and Ireland
$\square$ Mainland Europe
$\square$ Nordic countries

Figure 2 Retailer sample, main countries of operation

represented may be grouped as shown in Figure 1.

The retailer sample covers a number of countries, though it is focused on the UK. The main countries represented are as shown in Figure 2.

Thus, a range of retailers is considered, though any results cannot be considered statistically significant. The aim, however, is to provide some useful insight into the role that CRM plays within such organisations, and hence proposes a framework relating to best practice, rather than developing prescriptive solutions that are likely to be limited in their application.

\section{THE VALUE OF A CRM APPROACH}

Before evaluating the application of CRM in practice, it is worth noting the importance of the data captured compared to other data sources. In the interviews with retail practitioners, the improved understanding provided by data captured using a loyalty programme is made clear in the following quotes.

'One of the first learning experiences was that what people said was different to what they actually did. They would say yes or no to something, but their behaviour was different.' 
'[In our in-store surveys,] most customers would claim that they visited weekly. The reality was less than twice a month [as shown by our loyalty card data]. Customers felt that they visited [the store] weekly because they walked past it [on the High Street] every week.'

'Customers will always tell you something that they think you want to know. A customer that is less affluent is not going to admit that they go in and buy [the] cheapest possible products, because they have a personal image and they don't wish to say that. You have to interpret that data. Whereas [with] our data, we know exactly what they have bought, therefore it's a lot more accurate, a lot more valuable, there's a lot more in it.'

'Measurement of promotions would become much more difficult. We would not be able to look at how we are affecting different types of consumers; we would only be able to see that these promotions produce an uplift in sales on an aggregate level. We wouldn't be able to see who was responding to it, whether it was [a] change from other products.'

Thus, a loyalty programme provides data that are both trusted, as a true reflection of customer's actions, and in-depth, allowing for analysis that focuses on the customer, rather than the store or product.

\section{THE STRATEGIC PERSPECTIVE}

The use of CRM is both varied and extensive. The interviews with retailers, and associated third parties, provide examples of CRM in practice. To structure the responses and to reflect the strategic impact of employing CRM, an adaptation of Kaplan and Norton's architecture for a balanced scorecard approach to management strategy ${ }^{10}$ is employed. This identifies the following key perspectives: financial, customer, internal, learning and growth. In this adaptation, the:

- customer perspective focuses on demand issues, and in particular on the goals of the key customers, who represent the retailer's financial objectives;

— internal perspective focuses on management, systems and organisational issues, and in particular on ensuring the constant supply and provision of the customer proposition, that fulfils the key customers' goals and hence the retailer's financial objectives;

- learning and growth perspective focuses on future development, and in particular on the learning required to continually develop a successful customer proposition, that fulfils the key customers' goals, and hence the retailer's financial objectives;

- financial perspective focuses on the shareholder view of the retail firm and, in particular, on the financial objectives of a retailer's vision and strategy.

\section{Customer perspective}

From the customer perspective, the retailer-customer relationship may be developed in a number of ways using CRM. The various tactics may be classified as offensive or defensive.

Offensive CRM tactics aim to increase customer expenditure, either on existing purchases or through the introduction of new purchasing opportunities. For example, retailers may attempt to develop customer spending on existing purchases by relating the size of a reward threshold to a percentage increase in existing spending patterns. Similarly, new purchase opportunities may be based on filling a perceived gap in existing purchasing patterns. 
Defensive CRM techniques aim to maintain current customer expenditure levels. For example, the impact of pricing changes by competitors may be analysed to ensure that any resulting price changes by the retailer concerned are optimised. Likewise, lost customer expenditure may be targeted by automatically triggering an incentive when there is a certain percentage decline in an individual customer's purchasing levels.

Furthermore, customer profile information, as well as customer sales information, may be used in developing sales. An example from a practitioner follows.

'X manufacturer wanted to promote product Y ... We then [identify] people who bought children's clothes (the size suggesting the age of their children) that would like to look at Y. We worked out this population who could buy Y. We then promoted to them and we sold more $\mathrm{Y}$ than any other retailer in the country. We continue to enjoy enhanced sales. That was a very cost effective promotion.'

While such 'success stories' appear to illustrate that CRM can be very effective, retailers are more reticent to discuss 'failure stories'. Moreover, they tend not to include the overall cost of running such schemes. It should also be noted that while CRM databases represent a huge potential for analysing individual customers, this may only be a technical capability, rather than actual practice. From the authors' experience, customer analysis is usually carried out at a group level, while customer communication may be tailored to the individual.

\section{Internal perspective}

From the retailer's perspective, there are many areas where CRM can be used to enhance, adapt or enforce the retailer's proposition. The associated supply issues in a retail environment can be divided into two major groups: product range and supplier relationships.

CRM can potentially provide a powerful information base from which to negotiate and work more effectively with suppliers, whether the information is freely shared, traded or kept secret by the retailer, as the following example shows.

'In the cake market, our [supplier] has been in a position to suggest we reduce the range. In narrowing the range, however, it is essential to ensure that the candidates for reduction include those products that have the lowest customer loyalty or are most frequently substituted, and not simply those products with the lowest sales and lowest profitability.'

At the product level, CRM potentially provides retailers and suppliers with valuable information for measuring and improving the effectiveness of the marketing mix: product, place, price and promotion, as the following example illustrates.

'A supplier of yoghurt was able to identify some areas of under-distribution based on an analysis of repeat sales of similar products. We were able to make the change based on their understanding in [our] stores.'

It is worth noting that third-party information may be additionally employed to understand fully external reasons for any changes in demand.

\section{Learning and growth perspective}

One of the major advantages claimed by CRM solutions providers is that CRM may provide a powerful platform from which to understand customers better and so improve the retail proposition 
accordingly. In theory, retailers employing loyalty programmes can segment their customer base down to individual customers, and practise one-to-one marketing, as advocated by Peppers and Rogers. ${ }^{11}$ In practice, however, apart from personalisation for direct mailings, the number of segments used is generally limited, typically between ten and 100, though for some detailed research it may be much higher.

All retailers interviewed confirmed that their customers are all different, but often correspond to Pareto models, as in these two examples.

' $70 \%$ of the sales came from $30 \%$ of the customers, $80 \%$ of the profit came from $20 \%$ of the customers.'

'The top $20 \%$ to $25 \%$ of customers will account for $50 \%$ of the profit. The top $40 \%$ of customers usually work out at $90 \%$ of the profit.'

Understanding such differences helps to focus the retail proposition on the key current and future customers. The interviewed retailers aim to translate increased understanding of current customer behaviour into a more effective and efficient marketing strategy in the future. Moreover, CRM tools may be used to identify and exploit new growth opportunities, as illustrated by the following comments.

'We identified very early on, for a [large number] of shoppers there weren't many holes in the basket. So ... what do I do? Answer: sell [them] something else ... So we posed the question very early on of how do you expand the range of services that you offer'’

The key to exploiting fully these opportunities for growth appears to be the identification of current customer characteristics that closely relate to a new product or service. An obvious example might be exploring the opportunity to sell toys to customers buying children's clothes.

\section{Financial perspective}

The retailers interviewed were very wary of discussing the financial perspective of CRM in detail. What emerges is that while measures of financial performance are mixed, it is agreed that a loyalty marketing programme is a long-term commitment and may require extended financial investment.

Earlier research by Cuthbertson ${ }^{12}$ suggests that efficient store-based schemes appear to break-even when turnover increases by around 3 per cent to 4 per cent. How quickly each scheme reaches this point depends on several factors such as: the set-up costs, the take-up of the card, as well as the overall turnover and profitability of the retailer.

Apart from the operational costs of loyalty marketing, another cost occurs where retailers offer rewards to their customers. This can be extremely expensive and may appear to dwarf other costs, though it may include a large degree of supplier funding. On the other hand, loyalty marketing may provide valuable information that enables a business to reduce costs, such as inventory managers, merchandisers, buyers and suppliers. This positive contribution may be significant.

Clearly, some retailers consider the costs of CRM approaches to outweigh the benefits, as Safeway, UK, conceded in 2000:

'We have benefited from the loyalty card, but in the last 12 months we don't think the benefit has been anywhere near the $£, 50$ million cost. ${ }^{13}$

It is difficult, however, to calculate independently the effect of running a 


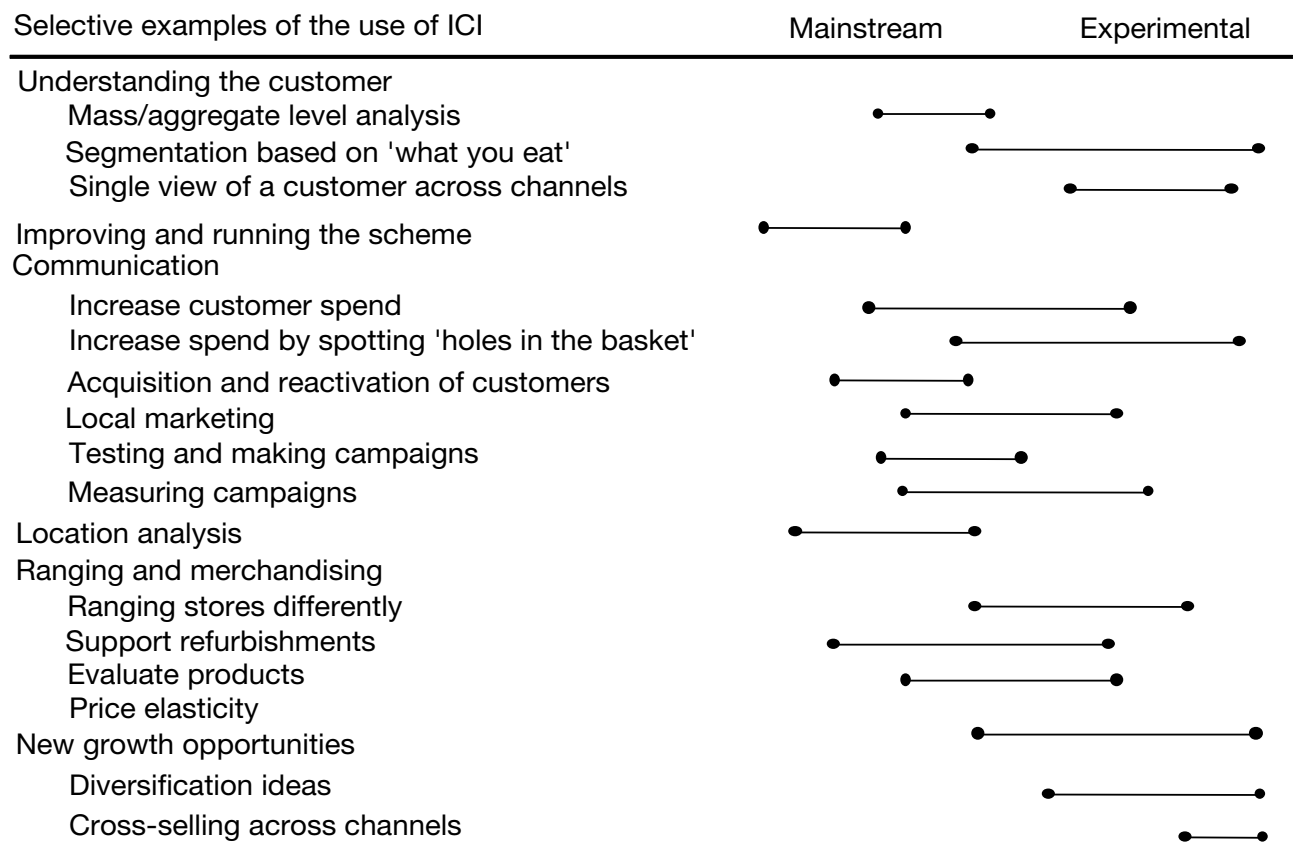

Figure 3 Summary of the use of individual customer information

CRM programme, though some companies, such as KPMG, do offer such a service. For example, a scheme may provide the vehicle for a promotion, but the scheme is just one part of the retailer marketing mix so it is difficult to separate out the cost of implementing the scheme.

In the final analysis, how much a retailer is willing to invest to achieve loyalty objectives and how long it can afford to wait for the results are clearly crucial, as shown in this quote.

'Our competitor's advantage is that they are doing so well, and they are getting very good press. They can afford to try things and fail ... what if we start launching all these initiatives and they fail? Whatever we do has to be a success.'

This illustrates the fact that CRM is very dependent upon the retailer's own business situation and the customers that they are trying to reach.

\section{CRM IN PRACTICE}

There are many CRM tools available to retailers, from full-scale enterprise-wide solutions, such as Siebel, to subscription services, such as Experian's Truvue. This is a continually evolving field. The potential use of CRM is therefore extensive, ranging from the more obvious direct marketing initiatives to much broader issues, such as retailer power within the supply chain. In reality, despite the huge capability of the tools available, the use of CRM techniques is generally more limited, as shown in Laine's ${ }^{14}$ summary of the use of CRM-based individual customer information (ICI) by certain grocery retailers (Figure 3 ).

As might be expected, the general process usually begins with experimentation followed by mainstream adoption.

In order to understand the importance of any of these CRM activities for a particular retailer, it is necessary to 
Purchaser: customer card usage

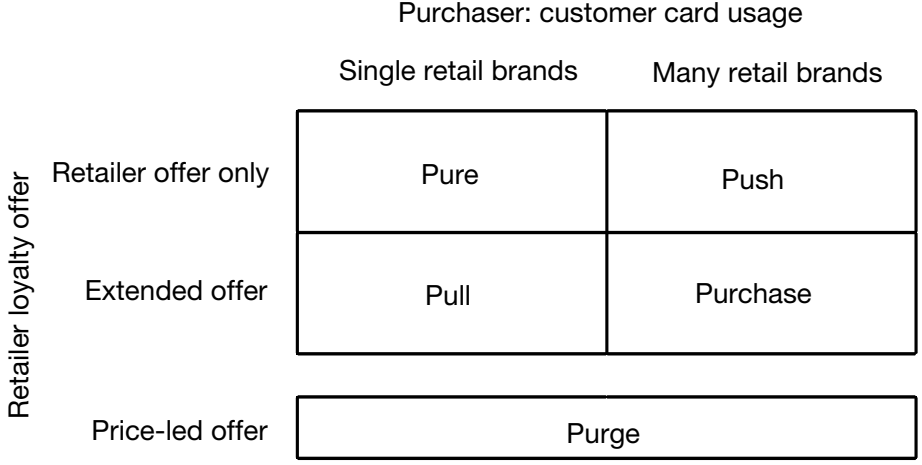

Figure 4 The purchaser-purveyor loyalty matrix

understand their overall loyalty marketing strategy.

\section{LOYALTY MARKETING STRATEGIES}

The purchaser-purveyor loyalty matrix developed by Cuthbertson and Bell ${ }^{15}$ proposes five distinct loyalty marketing strategies: pure, pull, push, purchase and purge. The matrix axes consider the customer (purchaser) and retailer (purveyor) view of loyalty schemes, and can be represented as shown in Figure 4.

Different loyalty strategies are appropriate for different retailers, depending upon their marketing mix and competitive position. In brief:

- pure loyalty strategies are primarily aimed at existing customers and focus on the retailer's product and service offer;

- push loyalty strategies are primarily aimed at pushing customers towards the retailer and focus on the retail location or channel;

- pull loyalty strategies are primarily aimed at pulling customers towards the retailer or particular purchases and focus on retailer promotion;

- purchase loyalty strategies are primarily aimed at increasing the number and value of purchase transactions, regardless of which individual retailer benefits;

- purge loyalty strategies are primarily aimed at the retailer purging all unnecessary costs and focus on providing all customers with the lowest possible price.

An individual retailer may have elements of more than one of these strategies, though there will usually be a focus on one or two. For example, Tesco in the UK, while clearly focused on price and product, can be considered to have a combined push and pull strategy as far as loyalty marketing is concerned. The Tesco Clubcard loyalty programme includes partner organisations, such as Marriott, Beefeater and Powergen, where customer spending accrues points on the Tesco Clubcard, thus pulling the customer towards Tesco, where some of the benefit accrued in the form of money-off vouchers can be redeemed. At the same time, Clubcard members may also collect points towards third-party offers, such as the collaboration with Air Miles providing travel products. These offers pull the relevant Air Miles collecting customers towards Tesco.

At this point, it is worth noting that the purchase loyalty strategy is not adopted by retailers per se, but rather by coalition loyalty programme 
providers, such as Nectar in the UK or Payback in Germany, or by financial service providers, such as MasterCard or Visa. In either case, loyalty is focused on the card, and the associated transactions, rather than any particular retailer.

From this research, it is possible to indicate the key measures and information issues, as well as the relative importance of different uses of CRM based on the loyalty marketing strategy adopted by a retailer.

\section{Pure loyalty strategies}

Pure loyalty strategies are often adopted by retailers where the physical exchange of product and service with a particular retailer is crucial. The service provided by store staff plays a critical role in such relationships. For example, department stores, such as John Lewis (Account Card) in the UK, often follow a pure loyalty marketing strategy.

Much of the communication and information shared within this relationship is qualitative, and includes the way in which staff dress and approach customers, as well as any quantitative information exchanged. While this situation provides many opportunities to strengthen the emotional element of the retailer-customer relationship, it may make it difficult to track the relationship over time. Thus, the development of a loyalty scheme should be carefully considered. Some CRM techniques can be employed to increase customer spending based on an understanding of past customer expenditure.

For example, using CRM techniques, retailers may attempt to increase previous customer spending levels by relating the size of a future reward threshold to past spending patterns, as shown in this quote.
'Let's say that weekly you might typically spend $\mathcal{K}^{7}$, you [might] get an $£^{8} 8$ coupon. So the coupon is aimed at a very reasonable level for you, but actually the coupon pays for itself by the fact that you actually spend the extra money to get the money off.'

Key measures tend to be focused on increasing the expenditure and profitability of existing customers. Successful pure loyalty strategies tend to rely on excellent customer specific marketing, based on loyalty (or store) card information.

From the discussions, a typical example of the relative importance of the different roles of CRM may be represented by Figure 5 .

\section{Pull loyalty strategies}

Pull loyalty strategies are often adopted by retailers where their core product range is largely considered as interchangeable with those of competitors, and the promotion of the retail brand, often through association with other brands, is crucial to pull customers towards the retailer. Thus, communication and promotion are employed as a means of differentiating between otherwise similar retail offers. For example, petrol or grocery retailers, such as Shell (Clubmart) in Germany or Albert Heijn (Bonuskaart) in the Netherlands, may follow a pull loyalty marketing strategy (often in combination with a push loyalty strategy).

Any information captured by the retailer may be useful in such a strategy. CRM must be employed to ensure that the offer is differentiated. For example, CRM is particularly useful in developing promotional activities as a means of differentiation. The impact of different types of campaigns for different customer groups can be accurately measured. There can be an audit trail to measure 


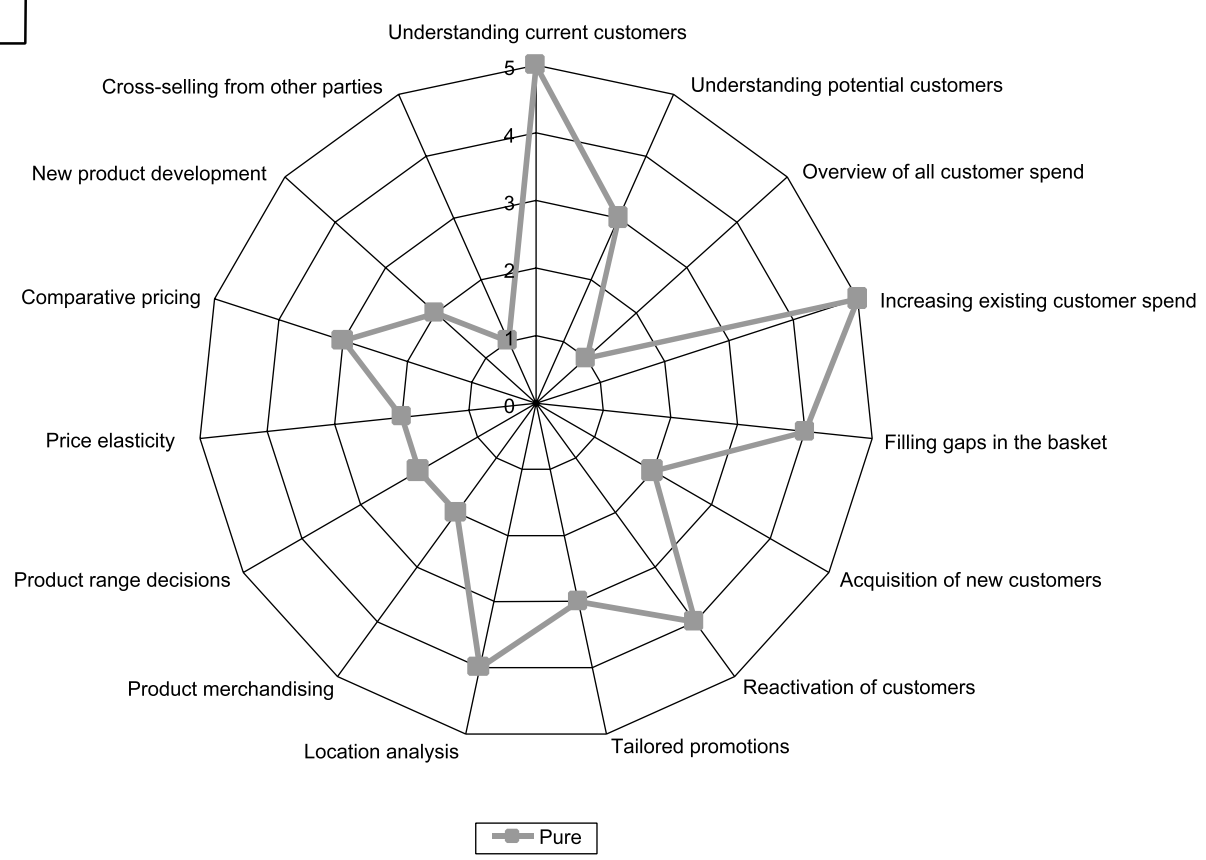

Figure 5 Example of relative importance of CRM practices - Pure loyalty strategy

the impact of a campaign, enabling the retailer to act appropriately, as the following quote suggests.

'We gather our data every night and the next day we start populating our databases. We can see success within 24 hours for a particular campaign ... We can actually recreate all those campaigns and calculate what the value was. You can measure exactly what you get.'

Customer incentives and rewards can be based on the analysis of similar customers or promotions. Importantly, the impact of such incentives can be accurately measured. Moreover, redemption rates for targeted customer groups are usually higher than in broad non-targeted promotions. For example,

'As we get to know the customer better, the targeting ... gets more and more relevant ... The redemption levels are so high and vary very dramatically across areas. For example, redemption is about 70\% [in one category].'
High redemption rates are mentioned as one of the valuable learnings, which encourage retailers to do more analysis with the customer data available and so differentiate further by offering highly relevant promotions.

Detailed customer information identifying which customers buy which products may also be important to suppliers, as it helps them to develop differentiated products and promotions relevant to particular customer groups, as the following quote illustrates.

'What we intend to do is basically give weekly web-based reports to manufacturers on their product performance. So rather than send them the raw data, we'll send them reports: this was the promotion, here are the demographics of the people who have taken up the promotion. Here is what we thought on who would take it and didn't take it etc. Very valuable.'

Key measures tend to be focused on increasing the expenditure and 


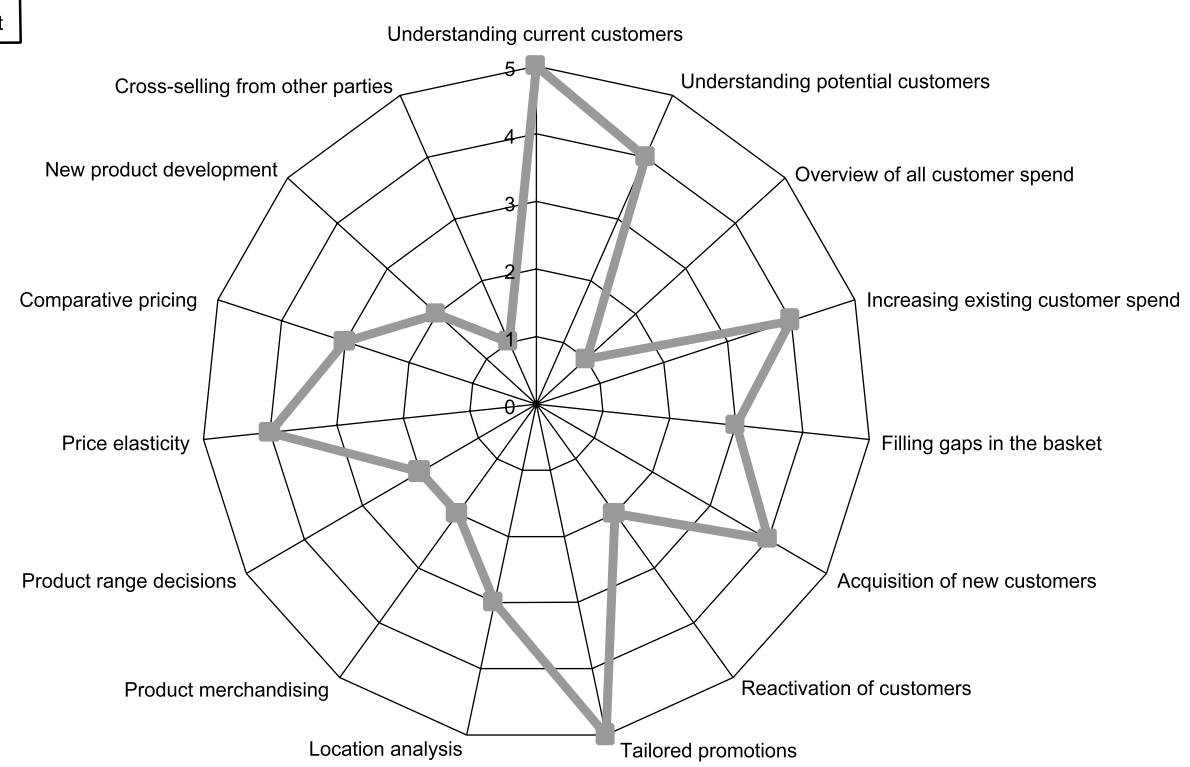

Figure 6 Example of relative importance of CRM practices - Pull loyalty strategy

profitability of existing customers, while simultaneously attracting new customers. To continue to increase the expenditure of existing customers, successful strategies appear to rely on excellent customer-specific marketing based on CRM data. To attract new primary customers, good external market research, or excellent marketing instincts, may also be required.

From the discussions, a typical example of the relative importance of the different roles of CRM may look as shown in Figure 6.

\section{Push loyalty strategies}

Push loyalty strategies are often adopted by retailers where their core product range is largely considered as interchangeable with those of competitors, and the visibility and accessibility of the retail brand is crucial in pushing customers towards the retailer. In overall retailing terms, this usually means providing a large store network across a range of formats to meet different customer purchasing needs. In terms of loyalty programmes, this often means that benefits accrued at one retailer may only be spent at the target retailer. Customer communication is critical in pushing the customer in the right direction. For example, petrol or grocery retailers, such as Tesco (Clubcard) in the UK, may follow a push loyalty marketing strategy (often in combination with a pull loyalty strategy).

Any information captured by the retailer may be useful in such a strategy, especially location-related information. CRM must be employed to ensure that the retail offer is visible, accessible and relevant to the local customer. CRM can play a major role in tailoring the proposition for the relevant marketplace. For example, no product may be 


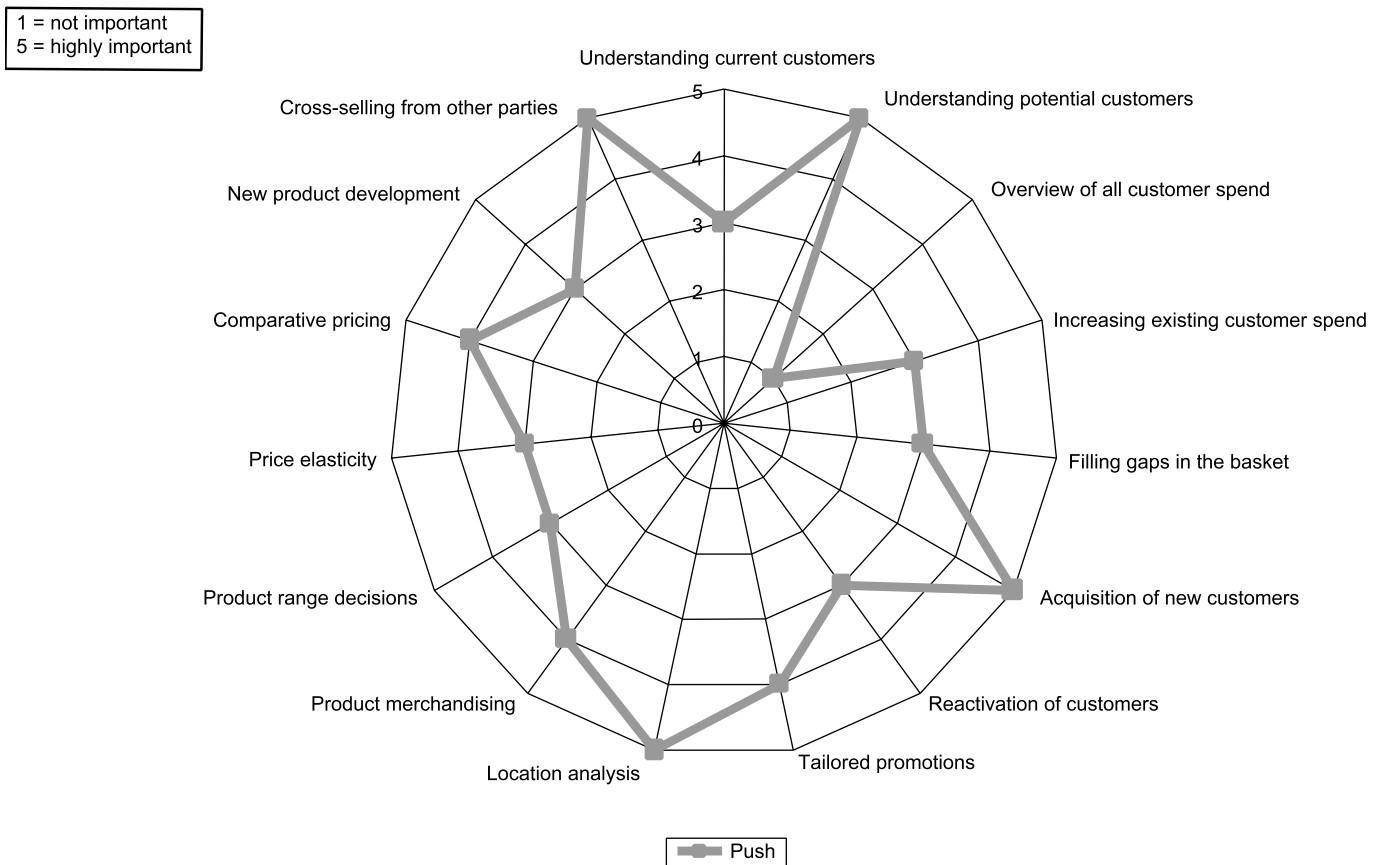

Figure 7 Example of relative importance of CRM practices - Push loyalty strategy

de-listed at a local store before analysing who actually buys it.

'We analysed who buys these [products] and it appeared it was just the top 20\% [of customers]. So ... it was a very important product. Our best customers wanted to buy that product. If they couldn't buy that, they would have gone somewhere else to buy that product. If it had been de-listed because the manufacturer had stopped making it, we would then have said to those customers [that] we are very sorry, but the manufacturer has stopped producing this particular product, here is an alternative product and here is a voucher for you to try it. Because we don't want to lose them.'

Furthermore, following such a strategy may not require changing the overall proposition, but rather emphasising the elements that appeal to a particular marketplace.

Key measures tend to be focused on attracting potential customers and assessing the suitability of different locations. Such strategies tend to rely on a combination of external market research, as well as CRM-based information.

From the discussions, a typical example of the relative importance of the different roles of CRM may look as shown in Figure 7.

\section{Purchase loyalty strategies}

Purchase loyalty strategies are not adopted by retailers per se, but rather by coalition loyalty programme providers, such as Nectar in the UK, or by financial service providers, such as MasterCard. In either case, loyalty is focused on the card, and the associated transactions, rather than any particular retailer. The key is to provide the customer with a range of retail opportunities that closely fit the customer's profile. Thus, CRM not only provides the communication platform for cross-selling, but also for understanding 


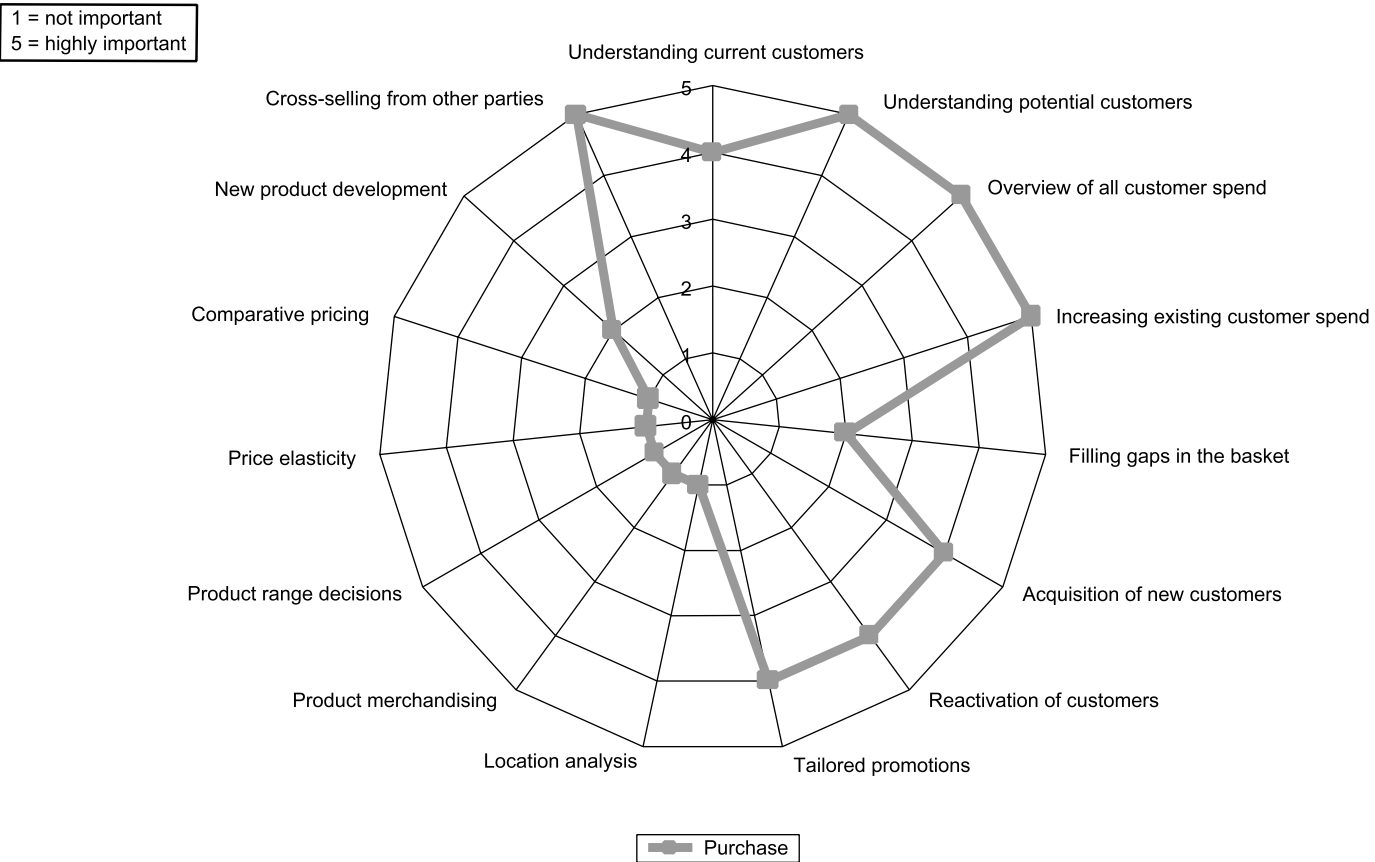

Figure 8 Example of relative importance of CRM practices - Purchase loyalty strategy

customer needs, so recruiting (or delisting) the necessary retailers to provide those customer needs. In theory, this may benefit both customer and retailer.

'Rob Gierkink, the chief executive of Loyalty Management UK, which runs Nectar, is adamant his approach is superior because with the opportunity of earning points at nine different companies, customers can clock up more points, more quickly. ... Although the cons of a multiple-member scheme mean that customers are loyal to Nectar rather than the individual retailing brand, Mr Gierkink says the pros include access to vastly more data about shopping habits at a far cheaper cost ... Using Nectar's direct mailings, which go to 12 million UK households, the likes of Sainsbury's can target people who currently buy their groceries elsewhere. ${ }^{16}$

Key measures tend to be focused on up-selling, cross-selling and attracting new customers. Such strategies tend to rely on the power and validity of the analysis of the retailer-combined CRM-database. From the discussions, a typical example of the relative importance of the different roles of CRM may look as shown in Figure 8.

\section{Purge loyalty strategy}

Purge loyalty strategies are often adopted by retailers where the focus is on providing an Every Day Low Price (EDLP) strategy. This strategy is often heavily reliant on supply rather than demand issues, particularly in terms of buying. Economies of scale are a distinct advantage. For example, general merchandise retailers, such as Wal-Mart in the USA, may follow a purge loyalty marketing strategy.

With such an emphasis on price and therefore cost, CRM tools are often seen as too costly in this approach. Large 
amounts of data may still be collected but at store and product level, rather than at the customer level.

'Wal-Mart has created what analysts believe is the largest and most complex commercial database. The Arkansas-based company recently doubled the size of its central data warehouse, which can store and analyse more than 200 terabytes of information. ... Put another way, the Wal-Mart database could store all the books and records in the Library of Congress - twenty five times over.

Such scale is one of the more dramatic aspects of the rapid accumulation by companies of information about sales and customers ...

Companies such as Wal-Mart regard the ability to analyse huge quantities of information as a strategic asset. Its database is the foundation of a sophisticated system that enables the company to track and predict demand for consumer products. ${ }^{17}$

Key measures tend to be focused on increasing the price competitiveness of the retailer's product offer. This tends to require excellent external market research on competitors, rather than CRM-based information. Thus, the relative importance of the different roles of CRM are all marginalised.

\section{CONCLUSION}

This paper provides an insight into the role of CRM within loyalty marketing. From the strategic perspective, CRM may potentially provide benefits for customers, retailers and suppliers, not only in commercial terms, but also in terms of individual and organisational learning and development. These benefits and developments are not, however, universal. By classifying different loyalty marketing strategies, it can also be shown that CRM plays a different role within an organisation depending on the marketing strategy adopted. This may have implications for managerial decision making throughout the CRM development life cycle, in terms of appropriate hardware and software platforms to the most relevant analyses and performance measures to adopt.

CRM clearly has the potential to help strengthen loyalty and build profitability, though it can be very expensive to implement. CRM techniques allow the retailer to focus on developing customer profitability, rather than aggregate profitability. This allows for a more targeted use of marketing and operational resources. Furthermore, loyal and profitable customer activity can be tracked to facilitate continually relevant retail development. Thus, CRM activities can be very effective in enhancing customer loyalty for profit. They cannot, however, create it on their own. This can only be achieved through understanding the relevance of such tools and techniques to the overall loyalty marketing strategy and applying them accordingly. Different priorities should be given to different CRM activities, depending upon the particular retail situation.

\section{Acknowledgments}

This paper is based on some of the work from the Loyalty 4 Profit research programme sponsored by KPMG International. Further information may be found at www.loyalty4profit.com.

\section{References}

1 Galbreath, J. (1998) 'Relationship management environments', CreditWorld, November-December, pp. 14-21.

2 http://searchcrm.techtarget.com/sDefinition/0, sid11_gci213567,00.html

3 Woolf, B. P. (1996) 'Customer specific marketing', Teal Books, USA.

4 Crosby, L. A. and Johnson, S. L. (2000) 'What to do before going 1-to-1', Marketing Management, Vol. 9, No. 4, pp. 15-21.

5 Mitchell, A. (2003) 'CRM failing as it yields one-sided relationships', Precision Marketing, 31st October, p. 14.

6 Davids, M. (1999) 'How to avoid the 10 biggest 
mistakes in CRM', Journal of Business Strategy, Vol. 20, No. 6, pp. 22-26.

7 Barlow, R. G. (2001) 'Loyalty marketing: What is its role in a CRM world?', European Retail Digest, No. 31, pp. 9-11.

8 Hirschowitz, A. (2001) 'Closing the CRM loop: The 21st century marketer's challenge: transforming customer insight into customer value', Journal of Targeting, Measurement and Analysis for Marketing, Vol. 10, No. 2, pp. 168-178.

9 Starkey, M. and Woodcock, N. (2002) 'CRM systems: Necessary, but not sufficient. REAP the benefits of customer management', Journal of Database Marketing, Vol. 9, No. 3, pp. 267-275.

10 Kaplan, R. S. and Norton, D. P. (2001) 'The strategy-focused organization', Harvard Business School Publishing Corporation, pp. 76-77.

11 Peppers, D. and Rogers, M. (1993) 'The one to one future: Building relationships one customer at a time', Doubleday, New York.

12 Cuthbertson, R. (2000) 'Loyalty cards: A research report on loyalty cards in European retailing', KPMG, London.

13 Hollinger, P. (2000) 'Safeway announces the emperor has no clothes', Financial Times, 5th May, p. 29.

14 Laine, A. (2001) 'Information from the masses', OXIRM, Oxford.

15 Cuthbertson, R. W. and Bell, R. (2001) 'The purchaser-purveyor loyalty scheme matrix',

Proceedings of EAERCD, Tilburg, The Netherlands, June.

16 Mesure, S. (2003) 'Loyalty card costs Tesco f,1 billion of profits - but is worth every penny', The Independent, 10th October, p. 24.

17 London, S. (2002) 'Wal-Mart doubles size of data warehouse', Financial Times, 15th June, p. 12. 